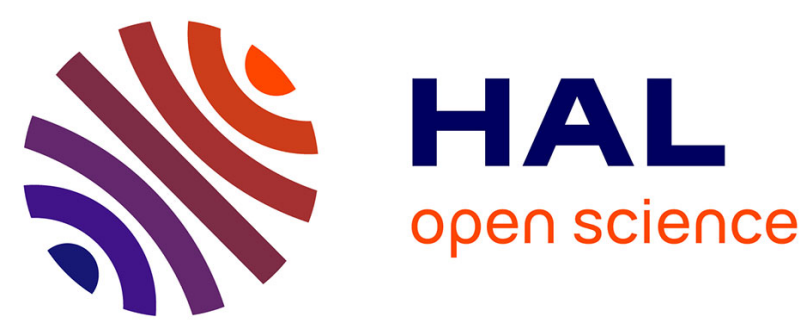

\title{
Sustainable Maintenance and Repair of RC Coastal Structures
}

\author{
Emilio Bastidas-Arteaga, Franck Schoefs
}

\section{To cite this version:}

Emilio Bastidas-Arteaga, Franck Schoefs. Sustainable Maintenance and Repair of RC Coastal Structures. Proceedings of the ICE - Maritime Engineering, 2015, 168 (4), pp.162-173. 10.1680/jmaen.14.00018. hal-01211213

\section{HAL Id: hal-01211213 \\ https://hal.science/hal-01211213}

Submitted on 4 Oct 2015

HAL is a multi-disciplinary open access archive for the deposit and dissemination of scientific research documents, whether they are published or not. The documents may come from teaching and research institutions in France or abroad, or from public or private research centers.
L'archive ouverte pluridisciplinaire HAL, est destinée au dépôt et à la diffusion de documents scientifiques de niveau recherche, publiés ou non, émanant des établissements d'enseignement et de recherche français ou étrangers, des laboratoires publics ou privés. 
Please cite this paper as:

Bastidas-Arteaga E. and Schoefs F., (2015). Sustainable Maintenance and Repair of RC Coastal Structures. Proceedings of the Institution of Civil Engineers: Maritime Engineering. http://dx.doi.org/10.1680/maen.14.00018

\title{
Sustainable Maintenance and Repair of RC Coastal Structures
}

\author{
Emilio Bastidas-Arteaga*, BSc, MSc, PhD, Associate Professor \\ Institute for Research in Civil and Mechanical Engineering (GeM - UMR CNRS 6183), Sea and Littoral Research \\ Institute (IUML - FR CNRS 3473), Université de Nantes, Nantes, France \\ Franck Schoefs, PhD, Professor \\ Institute for Research in Civil and Mechanical Engineering (GeM - UMR CNRS 6183), Sea and Littoral Research \\ Institute (IUML - FR CNRS 3473), Université de Nantes, Nantes, France
}

\begin{abstract}
Many agencies worldwide have to manage structurally damaged reinforced concrete (RC) coastal infrastructure subjected to chloride ingress that require significant repairs. These repairs should ensure optimal levels of serviceability and safety and minimise costs and environmental impact. However, there is a wide quantity of protocols, techniques and materials for repair and there is no much information about their durability performance. This paper proposes a methodology for evaluating, comparing and/or improving sustainability of maintenance strategies. It was developed within the framework of the MAREO project in collaboration with the different stakeholders involved during the whole structural lifetime. It is based on probabilistic modelling of deterioration and repair, and the sustainability assessment considers costs (with conventional and intergenerational discounting), $\mathrm{CO}_{2}$ emissions and waste generation. The methodology is illustrated with a numerical example aiming to evaluate and improve the sustainability of a repair technique for RC structures subjected to chloride-induced corrosion damage. Overall results indicate that sustainable solutions increase global costs but they could reduce significantly environmental impact.
\end{abstract}

\section{Keywords chosen from ICE Publishing list}

Maintenance \& Inspection; Concrete Structures; Sustainability

\section{List of notation}

$C_{j}(t): \quad j^{\text {th }}$ expenditure at time $t$

\footnotetext{
Address: 2 rue de la housinnière BP 92208, 44322 Nantes Cedex 3, France.

Phone: +33 251125524

Email: emilio.bastidas@univ-nantes.fr
} 
$C_{\text {env: }} \quad$ environmental chloride concentration

$d$ : discount factor

$d_{a}$ : intergenerational discount factor

MOI: multi-objective index

$p$ : $\quad$ parameter indicating the importance given to deviations from the ideal solution

$r$ : discount rate

$r_{i}$ : intergenerational discount rate

$T_{a}$ : $\quad$ period of analysis

$t_{c r}: \quad$ time to corrective repair

$t_{p r}: \quad$ time to preventive repair

$W(t)$ : weight used to discount $C_{j}(t)$ to the present value

$W_{c}(t)$ : conventional weight

$W_{l}(t)$ : intergenerational weight

$w_{i}$ : $\quad$ weighting factor of the optimisation criterion $f_{i}$

$x_{i}^{*}: \quad$ ideal solution of the optimisation criterion $f_{i}$

$x_{i} * \quad$ anti-ideal solution of $f_{i}$

$\Delta t \quad$ length of the inspection interval

\section{INTRODUCTION}

\subsection{Motivation, industrial and scientific challenges}

Coastal infrastructures are critical and strategic assets for the development of any country. For example, ports handle $80 \%$ of the nation trade and provide strategic places for the fishing industry, leisure activities and European defence. 564 types of ports can be found along the French coastline (Boéro et al., 2009). Depending on their use, location and construction dates, ports components are generally constituted by several materials (Díaz Rato et al., 2008). Concerning French ports, most part of their components were built in masonry (33\%) followed by steel $(28 \%)$, reinforced concrete $(R C)(24 \%)$ and other materials (15\%) (Boéro et al., 2009$)$. On the overall, the majority of ports $(60 \%)$ were built before 1955 and significant damage has been reported for their RC components (Boero, 2010; Rosquoët et al., 2006).

The durability of RC structures placed in coastal areas is largely affected by chloride-induced corrosion. RC has been widely used in the construction of structures or structural components for many coastal assets. The kinematics of the deterioration mechanisms is controlled by material properties and exposure conditions (E. Bastidas-Arteaga and Stewart, 2015a, 2015b). However, the consequences of chloride-induced corrosion damage in terms of serviceability and safety that define inspection and maintenance strategies are different for each the type of asset: ports (Boéro et al., 2009; Lefler and Rey Romero, 2009), buildings (Medeiros et al., 2013), bridges (Cheung et al., 2009), coastal defences (Alani and Chen, 2012), etc. This is due to the fact that failure consequences differ for each type of structure. Consequently, maintaining this ageing $R C$ infrastructure in service and safe becomes a main challenge for managers and owners.

Currently, the rehabilitation market represents half of the building trade activity and a significant percentage of public works in France. Companies consider that the rehabilitation activity will develop in the public works field and may reach a volume near than construction of new structures. Furthermore, environmental considerations have raised important questions regarding the new developments, environmentally friendly solutions, and/or decommissioning of existing infrastructure. The maintenance planning optimisation is therefore a major challenge with multiple constraints imposed by economical, environmental, and societal considerations. 


\subsection{The MAREO Project}

Within this context, the main objective of the MAREO ${ }^{\dagger}$ project (2007-2012) was to provide a comprehensive framework to improve the sustainability, effectiveness, reliability and long-term performance of maintenance strategies for RC coastal structures subjected to chloride ingress. The project had two scientific objectives. First, to evaluate and compare the effectiveness of repair techniques within the context of sustainable assessment of existing RC structures. Second, to identify and quantify uncertainties and hazard sources related to repair, material properties, exposure and models. The project therefore relies on methodologies for risk analysis and assessment.

The project received in 2006 the support of the 'Pole Génie Civil et Eco-construction' and 'Maîtrice de Risques en Génie Civil' and it was granted in 2007 with a support of 1.04 million euros $(75 \%$ from the Loire-Atlantique region and $25 \%$ from the French government). The consortium gathered two port owners (Port of Nantes Saint-Nazaire, and General Council), four companies specialised in cost evaluation, modelling, construction and assessment of existing structures (Arcadis, Oxand, SEMEN-TP and ETPO) and seven research laboratories for: destructive and non-destructive testing and diagnosis (IFSTTAR), laboratory and tank tests (GeM, IFREMER, CERIB, LMDC), assessment of existing structures and reliability analysis (GeM, LMDC, CEREMA) with exchanges with the Trinity College Dublin.

The research work of the MAREO project was defined taking into account the feedback and requirements of all stakeholders involved during the structural lifetime. The following tasks were carried out:

1. identification of structural performance indicators: porosity, chloride diffision coefficient, chloride content and $\mathrm{pH}$ near the rebar;

2. definition of the relationships between these indicators and their comparison in terms of risk analysis. This implies particularly to consider modelling uncertainties and to propose other models based on non-deterministic approaches (physical or analytical response surfaces) and to identify uncertainties on performance indicators or influential factors and thereby to characterise the so-called intrinsic hazards;

3. selection of experimental devices and protocols (in laboratory or in situ), to identify and characterise failure mechanisms;

4. choice of computational methods for assessment of existing structures; and

5. development of a methodology for semi-probabilistic analysis through pilot studies on various components (Schoefs et al., 2010):

- repair and test of 20 beams exposed to chlorides during 80 years in the estuary of the Rance river in France where chlorides were transported by the wind and longterm splash exposure, and

- composite sticking repair with a carbon fiber reinforced polymer plate of RC beams for two harbours (Port of Nantes Saint-Nazaire and general council).

The main outputs were:

- the development of a complete protocol (natural and accelerated tests) for condition assessment of repair materials (Tran et al., 2015);

- the publication of guidelines for repair chloride-deteriorated structures (Schoefs et al., 2010);

- the quantification of uncertainties for chloride assessment and for repair techniques (Bonnet et al., 2009);

\footnotetext{
${ }^{\dagger}$ Maintenance and Repair of Concrete Coastal Structures: Sustainable Risk-Based Optimisation
} 
- the improvement of Non-destructive tests (NDT) and embedded sensors for chloride assessment (Du Plooy et al., 2013);

- the development of a model of chloride ingress into concrete (E. Bastidas-Arteaga et al., 2011) and a methodology for maintenance and inspection optimisation (Emilio Bastidas-Arteaga and Schoefs, 2012);

- the definition of new issues for future research: reliability assessment and risk analysis during repair operations, the need for optimizing the number of cores for condition assessment and the use of NDT combination for improving the reliability of diagnosis (Torres-Luque et al., 2014).

\subsection{Aims and scope}

This paper focuses on the developments around the concept of sustainable maintenance optimisation when significant repairs are required and long-term performance is pursued. The scope and needs for sustainable maintenance were defined in collaboration with the different stakeholders involved within the MAREO project. The proposed methodology considers both environmental and intergenerational consequences. Owners and managers searching for sustainable maintenance strategies could use the proposed approach to (i) improve the sustainability of a maintenance strategy and/or (ii) compare the sustainability performance of various strategies. The approach was formulated on the basis of the maintenance of RC ports subjected to chloride-ingress. Nevertheless, it can also be applied for other deterioration processes and/or materials.

Section 2 describes the general framework for sustainable maintenance proposed in this study. Sustainability of a maintenance strategy is evaluated in terms of three criteria described in Section 3 (costs, waste generation and $\mathrm{CO}_{2}$ emissions). Section 3 also presents the methodology for decision-making under multi-objective constraints. Finally, the proposed approach is applied to a numerical example that aimed at evaluating and optimising the sustainability of a maintenance strategy (Section 4).

\section{FRAMEWORK FOR SUSTAINABLE MAINTENANCE}

The conceptual framework proposed to evaluate and optimise the sustainability of maintenance strategies could be applied at two levels. It can be used to improve the sustainability of the formulation of a single maintenance strategy and/or it can be implemented to compare different strategies. The proposed framework accounts for the following aspects:

- the implementation of a deterioration model representative of the considered phenomenon (exposure and durability of construction and repair materials);

- the formulation of a maintenance strategy technically and economically feasible and that ensures optimal levels of serviceability and safety during the operational life;

- the implementation of an appropriate probabilistic framework for considering the uncertainties related to both the deterioration process and the inspection/maintenance actions;

- the establishment of criteria for the evaluation of the environmental impact; and

- the adoption of a multi-objective optimisation procedure to minimise costs and environmental impact.

Figure 1 compares the stages for obtaining a cost-effective or sustainable formulation of the maintenance strategy. The following stages are required to determine both results: (i) 
formulation of the maintenance technique, (ii) modelling of deterioration and maintenance actions, and (iii) Improvement of the formulation.

\subsection{Formulation of the maintenance strategy}

This is a crucial stage in the management process. The formulation should consider: the characteristics of the deterioration process, the stages of maintenance (i.e., inspection, repair), the maintenance philosophy (i.e., preventive or corrective) and the technical and economic feasibility of the selected technique.

Inspection results alert the owner/operator when a given deterioration threshold is reached. Destructive and non-destructive methods are employed to carry out inspections. Concerning non-destructive methods, visual inspection is usually used for evaluating the condition of RC structures (Roelfstra et al., 2004). However, for visual inspection, the assessment of the structural condition remains largely uncertain when inspection is undertaken. Other nondestructive techniques aim at quantifying the instant value or the evolution in time of a given variable (material strength, chloride concentration, corrosion rate, etc); nevertheless, their results are highly influenced by environmental conditions reducing its accuracy (Torres-Luque et al., 2014). Although destructive inspection techniques improve significantly the structural condition assessment, they are more expensive and require a larger number of tests when there is a larger variability of the inspected parameter.

The extent of damage assessed during inspection conditions the repair technique choice. Consequently, the formulation of the maintenance strategy (inspection and repair) depends on several aspects such as: the phenomenon inspected (material strength, chloride concentration, etc.); the size of the project (structural network, particular structure or component); the use of the structure (nuclear, transportation, etc.); the remaining lifetime; the location of the structure/component; and other socio-economic aspects such as priorities of the country, availability of resources, etc. To define an appropriate maintenance strategy, all the stakeholders that are linked to the structure during its life-cycle should participate in this stage.

\subsection{Modelling of deterioration and maintenance actions}

Experimental testing is the best way to determine and to improve the performance of repair techniques. However, given that these tests are generally expensive and time-consuming, numerical modelling of deterioration and repair actions is essential to study and/or to improve the effectiveness of maintenance strategy in most cases. Furthermore, the uncertainty related to the deterioration process and the maintenance actions should be considered to improve the predictability of the models. The main sources of uncertainty are related with durability properties of the construction and repair material, environmental actions (climate conditions, chloride concentration), loading and effectiveness of inspection and repair actions. Four types of methods can be used for modelling deterioration and repair (van Noortwijk and Frangopol, 2004): (i) failure rate functions, (ii) Markov models, (iii) stochastic processes, and (iv) timedependent reliability analysis. Each method has its advantages and shortcomings and it is more or less adapted for each maintenance problem (E. Bastidas-Arteaga, 2010). Although some specialised companies currently implement some of these aspects for lifetime assessment, research centres mainly carry out this stage. Realistic predictions also require experimental data for prediction and updating in addition to the feedback of contractors and agencies (Schoefs, 2014). 


\subsection{Improvement of the formulation:}

The performance of each maintenance strategy can be improved by optimizing its governing parameters. Classically, the optimisation function aims at minimising costs and then providing an optimal cost-effective formulation of the maintenance technique (Alani and Chen, 2012; Emilio Bastidas-Arteaga and Schoefs, 2012; van Noortwijk and Frangopol, 2004). Nevertheless, to reduce the environmental impact, it is necessary to include environmental constraints in the optimisation problem (Padgett and Tapia, 2013; Tapia and Padgett, 2015). Under these considerations, the optimisation leads to an optimal sustainable formulation of the maintenance technique (Figure 1). Mainly research centres carry out this stage. However, the diffusion of these techniques to consultants is imperative. Again, the feedback of contractors and agencies are essential to provide feasible results. Section 3 describes the criteria considered in this study for evaluating the sustainability of maintenance strategies.

\section{CRITERIA AND METHOD FOR SUSTAINABILITY ASSESSMENT}

The World Commission on Environment and Development (1987) defines sustainable development as: development that meets the needs of the present without compromising the ability of future generations to meet their own needs. To meet this goal, sustainable development must provide a balance between three components: environment, economy and society. The evaluation of the sustainability of the repair techniques is based on the comparison of three criteria: cost, waste generation, and carbon dioxide emissions. Society is not directly considered but it is indirectly implied in decisions affecting these components (Sánchez-Silva and Rosowsky, 2008). More criteria could also be included for a specific problem.

\subsection{Cost}

Two kinds of costs are usually considered in cost analysis: agency and user costs. Agency costs encompass the direct costs incurred by the owner/operator during the life-cycle. User costs represent the inconvenience and expenses incurred by users due to traffic disruption such as delay, operating and accident costs. Thoft-Christensen (2009) highlights the importance of including user costs in the analysis. These cost are specific for each type of structure and could be also considered in the proposed framework if the information is available. However, this work is only based on the available agency costs.

This study focuses on the sustainability of maintenance strategies for deteriorating structures. Then the direct costs incurred by the agency include only costs associated with maintenance (inspection, preventive and corrective repair). Initial construction and residual costs are not included in the analysis because it would be the same for all maintenance alternatives.

In life-cycle cost analysis, the present value life-cycle cost incurred during the period of analysis $T_{a}$ is computed as:

$$
E\left[C_{T}\right]=\sum_{t=0}^{T_{a}} E\left[C_{j}(t)\right] W(t)
$$

where $C_{j}(t)$ is the $j^{\text {th }}$ expenditure at time $t$. Basically, these costs depend on the properties of the original and repair material; and on the characteristics of the maintenance strategy (i.e., inspection interval, repair threshold, repair material and technique, etc.) and $W(t)$ is the weight used to discount $C_{j}(t)$ to the present value. Let $d$ denote the discount factor computed in terms of a standard discount rate $r$ : 
$d=1 /(1+r)$

Then, the conventional weight in a given period becomes:

$W_{c}(t)=1 /(1+r)^{t}$

Sumaila \& Walters (2005) and Prager \& Shertzer (2006) derived an intergenerational discount weight for computing net benefits from the use of environmental resources. Their formulation treats the benefits as accruing to the current generation (at standard discount rates) plus annual increments of new stakeholders who will enter to the future population divided by the generation length, $G$ :

$W_{I}(t)=d^{t}+\frac{d_{a} d^{t-1}}{G}\left[\frac{1-\left(d_{a} / d\right)^{t}}{1-\left(d_{a} / d\right)}\right]$

where $d_{a}$ is the intergenerational discount factor:

$d_{a}=1 /\left(1+r_{I}\right)$

where $r_{l}$ is the intergenerational discount rate.

\subsection{Waste generation}

Concrete has been recognised as the largest and most visible component of construction and demolition waste. It accounts for up to $67 \%$ by weight of construction and demolition waste ( $53 \%$ by volume), with only $5 \%$ currently recycled (American Institute of Architects, 1999). Therefore, waste generation should be included as a selection criterion for sustainable management.

A comprehensive assessment of waste generation should include waste generated during the production of the repair material and the repair operations. However, taking into account the difficulties in estimating the waste generated during the production of concrete, this study only considers waste produced during repair operations (demolition and rebuilding). Waste generation depends mainly on the characteristics of the repair technique - e.g., material durability. These characteristics will define the number of repairs during the analysis period or the repair rate and could be determined by a deterioration model.

\subsection{Carbon dioxide emissions}

Carbon dioxide emissions are one of the major causes of climate change (IPCC, 2007). Therefore, taking into account that the world's yearly production of 1.6 billion tons of cement accounts for about $7 \%$ of the global emissions of $\mathrm{CO}_{2}$ into the atmosphere (Kumar Mehta, 1997), the assessment of carbon dioxide emissions produced during repair operations is crucial for sustainable development. This analysis considers two sources of $\mathrm{CO}_{2}$ :

1. emissions produced during transportation of materials, equipment and waste, and

2. $\mathrm{CO}_{2}$ released during production of the repair material.

The emissions produced to repair $1 \mathrm{~m}^{3}$ of polluted concrete during transportation are calculated by summing the emissions released during provision of repair material, provision of equipment 
and disposal of waste. The emissions are computed in terms of the distances for provisioning repair materials and equipment and disposal of waste. Transportation emissions depend on the characteristics of the transportation vehicle (emissions in grams of $\mathrm{CO}_{2}$ per $\mathrm{km}$ ).

On the other hand, the $\mathrm{CO}_{2}$ released during production of the repair material (in $\mathrm{kg} \mathrm{CO}$ per year) is estimated in terms of the cement content per $\mathrm{m}^{3}$ of concrete (in $\mathrm{kg} / \mathrm{m}^{3}$ ) and the rate of $\mathrm{CO}_{2}$ emissions released during the repair material production (in $\mathrm{kg} \mathrm{CO}_{2} / \mathrm{kg}$ of repair material). The average $\mathrm{CO}_{2}$ production emissions ranges from 0.65 to $0.92 \mathrm{~kg}$ of $\mathrm{CO}_{2}$ per $\mathrm{kg}$ of cement across several countries (International Energy Agency, 2007). Since there is no information about the $\mathrm{CO}_{2}$ emissions related to the production of the repair products, a weighted average emission of $0.83 \mathrm{~kg} \mathrm{CO} / \mathrm{kg}$ of repair material is adopted herein. Again, the quantity of $\mathrm{CO}_{2}$ released during repair depends on the characteristics of the repair technique.

\subsection{Decision-making under multi-objective constraints}

The challenge in suistainable management of deteriorating structures lies in its multi-objective nature. Owners/operators are confronted to simultaneously satisfy several criteria such as: minimisation of cost, traffic disruptions and environmental impact on the one hand, and improvement of serviceability, functionality and safety on the other hand. Multi-objective optimisation techniques are appropriate to deal with this problem (Tapia and Padgett, 2015). Compromise programming is adopted herein to solve the multi-objective problem. Compromise programming minimises the distance from the set of Pareto optima to the so-called 'ideal solution'. The ideal solution is defined as the solution that yields simultaneously optimal values for all objectives. For $m$ objective functions, the ideal solution can be associated with the ideal objective vector: $f^{*}=\left[x_{1}{ }^{*}, x_{2}{ }^{*}, \ldots, x_{m}{ }^{*}\right]$. Where $x_{i}^{*}$ is the ideal solution of the optimisation criterion $f_{i}$ with $i=1, \ldots, m$. In this particular case there are three criteria to evaluate: (1) costs, (2) waste generation and (3) $\mathrm{CO}_{2}$ emissions. Since each criterion has its own system of units, this study uses a multi-objective index (MOI) to evaluate the sustainability of the maintenance strategy (Lounis, 2006). A MOI is defined for each technique as the value of the weighted and normalised deviation from the ideal solution $\mathbf{f}^{*}$ measured by the family of $L_{p}$ metrics. Thus, the 'satisfying' solution is the one that yields a minimum MOI:

$$
\operatorname{MOI}(\mathrm{x})=\left[\sum_{\mathrm{i}=1}^{\mathrm{m}} \mathrm{w}_{\mathrm{i}}^{\mathrm{p}}\left|\frac{\mathrm{x}_{\mathrm{i}}-\mathrm{x}_{\mathrm{i}}^{*}}{\mathrm{x}_{\mathrm{i}^{*}}-\mathrm{x}_{\mathrm{i}}^{*}}\right|^{\mathrm{p}}\right]^{1 / \mathrm{p}}
$$

where $w_{i}$ is the weighting factor of the optimisation criterion $f_{i}, p$ is a parameter indicating the importance given to deviations from the ideal solution, and $x_{i^{*}}$ is the anti-ideal solution of $f_{i}$. The value of $w_{i}$ varies between 0 and 1 with $\Sigma w_{i}=1$. The weighting factors depend mainly on the attitude of the owner/operator towards each criterion. The parameter $p$ varies between 1 and $\infty$. For $p=1$, all deviations from the ideal solution are considered in direct proportion to their magnitudes, which corresponds to a group utility (Duckstein, 1984). For $p=2$, a greater weight is associated with the larger deviations from the ideal solution and $L_{2}$ represents the Euclidian metric. For $p=\infty$, the largest deviation is the only one taken into account and is referred to as the Chebyshev metric or mini-max criterion and $L_{\infty}$ corresponds to a purely individual utility (Lounis, 2006). The Euclidian metric was adopted in this work to determine the sustainable repair strategy. 


\section{NUMERICAL EXAMPLE: MAINTENANCE OF COASTAL RC STRUCTURES SUBJECTED TO CHLORIDE INGRESS}

\subsection{Problem description and basic considerations}

This example illustrates the proposed framework for evaluating and optimising the sustainability of maintenance strategies. It focuses on the performance of a maintenance strategy for coastal RC structures in a chloride-contaminated environment. The characteristics and the requirements for the maintenance strategy were defined within the framework of the MAREO project. The adopted maintenance strategy has two steps:

- Inspection: it is carried out by analysing the concentration of chlorides at the cover depth on concrete cores (destructive method) at periodic inspection intervals of length $\Delta t$.

- Repair: if inspection results reveal larger corrosion initiation risks, the repair technique consists of rebuilding the polluted concrete cover using a commercial repair concrete.

This preventive repair strategy aims at avoiding corrosion initiation and ensuring an optimal safety level; however, additional repair costs could be incurred if corrosion has started at the inspection times.

Cost and environmental impact of the maintenance strategy depend on $\Delta t$. The determination of an optimal $\Delta t$ is very sensitive to the cost models. Therefore, to obtain realistic results, the costs were defined taking into account the average maintenance expenditures incurred by the port of Nantes Saint-Nazaire (Table 1). These costs are referred to an initial construction cost of 1000 units. Whereas preventive repair only considers the cost related to cover rebuilding, corrective repair also includes the costs of structural strengthening. Table 2 presents the parameters used to estimate waste generation and carbon dioxide emissions.

\subsection{Probabilistic modelling of deterioration and repair}

There is no in-field information about the long-term durability performance of the commercial repair concrete. Consequently, it is determined on the basis of (i) experimental results that provide some input parameters (Schoefs et al., 2010), (ii) literature review to complete missing information (Table 3), and (iii) a Markovian approach to model deterioration and repair (Emilio Bastidas-Arteaga and Schoefs, 2012). The main advantage of this Markovian approach lies in the consideration of the most important phenomena influencing chloride ingress and maintenance including environmental conditions, uncertainties and consequences of 'good' or 'wrong' decisions when there are imperfect inspections. However, other approaches for modelling deterioration and repair can be instead implemented for other materials, deterioration mechanisms and/or maintenance actions.

The inputs of the model are stochastic processes and independent random variables. The environmental chloride concentration $C_{e n v}$ was modelled as a stochastic process generated by independent lognormal numbers (log-normal noise) with a mean of $6 \mathrm{~kg} / \mathrm{m}^{3}$ and a coefficient of variation of 0.2 (Duracrete, 1998; Vu and Stewart, 2000). These values correspond to a splash and tidal exposure. Climate variations (temperature and relative humidity) are represented as a stochastic process using the Karhunen-Loève expansion (E. Bastidas-Arteaga et al., 2013). The considered climate conditions correspond with an oceanic climate with temperature and relative humidity ranging from 5 to $25^{\circ} \mathrm{C}$ and 0.6 to 0.8 for each year, respectively.

Table 3 presents the probabilistic models of the considered random variables. The mean of the chloride diffusion coefficient depends on the characteristics of the material. The mean of the chloride diffusion coefficient for the construction material was assigned according to 
experimental values (Saetta et al., 1993). The mean of the chloride diffusion coefficient for the repair material was defined based on experimental results obtained within the framework of the MAREO project (Schoefs et al., 2010).

The Markovian approach is used to estimate the expected times to preventive and maintenance repair as a function of $\Delta t$ (Figure 2). These results were obtained for a concrete cover of $5 \mathrm{~cm}$. As expected, the time to preventive repair, $t_{p r}$, is lower when the structure is inspected more periodically. On the contrary, less inspection implies that the time to corrective repair, $t_{c r}$, decreases. These times are used to determine $\Delta t$ that minimises both costs and environmental impact. In order to simplify the computation, the simulation results are adjusted to two analytical functions that allow to estimate $\mathrm{E}\left[t_{p r}\right]$ and $\mathrm{E}\left[t_{c r}\right]$ in terms of $\Delta t$ (Figure 2).

\subsection{Results}

Figure 3 presents the expected costs for the standard and intergenerational discounting. It is observed in all the cases that the costs of inspection and preventive repair decrease and the cost of corrective repair increases for larger $\Delta t$. This behaviour is explained by the fact that when $\Delta t$ is greater, most part of inspections detect that the components are corroded. On the contrary, when the structure is inspected regularly, repair is basically preventive, and therefore, the corrective repair expenditures diminish. In all cases, total costs are optimal when the structure is inspected every $20 \mathrm{yr}$ and $17 \mathrm{yr}$ for the standard and intergenerational discounting models, respectively. However, the optimum expected cost is different for both cases because future flows for the intergenerational model is important in comparison to the conventional model for the analysis period $T_{a}$. The differences between the optimum $\Delta t$ imply that the intergenerational discounting gives more importance to preventive maintenance.

Figure 4a provides the assessment of the multi-objective index for different inspection intervals and cost models. These results were obtained by assuming that the agency gives the same importance to costs and environmental impact - i.e., $w_{\text {cost }}=0.5, w_{\text {waste }}=0.25$ and $w_{\mathrm{CO} 2}=0.25$ in eq. 6. These curves follow the behaviour described in Figure 3 where there are inspection intervals that minimise the MOI. However, the computed optimum $\Delta t$ are higher than those estimated from the cost analysis: 21 and $19 \mathrm{yr}$ for the conventional and intergenerational discounting models, respectively. The increase in the inspection interval reduces the repair rate and then the expected total waste generation and $\mathrm{CO}_{2}$ emissions. However, the consideration of waste generation and $\mathrm{CO}_{2}$ emissions in the assessment of optimal $\Delta t$ induces overcharges. The selection of a given interval depends on the agency's policies. Consequently, the agency decides how much overcharges can be expended to reduce environmental impact. Socioeconomic aspects that are characteristic of a given company or country govern this decision.

Economic or environmental priorities are measured herein by the weighting factors (eq. 6). Thus, Figure $4 \mathrm{~b}$ shows the overcharges generated when the cost weighting factor varies between 0 and 1 for the optimal $\Delta t$ that minimise the $\mathrm{MOI}$ in each case. The estimation of the overcharges supposes that the waste and $\mathrm{CO}_{2}$ emission weighting factors are equal. The cost weighting factor $w_{\text {cost }}=1$ implies that the decision is controlled only by costs. In this case, environmental constraints are not considered, and then, the overcharges are zero. On the contrary, for $w_{\text {cost }}=0$, the overcharges lead to a maximum value. For the range of cost weighting factors presented in Figure $4 \mathrm{~b}$, the maximum overcharges are less than $6 \%$ and $13 \%$ for the conventional and intergenerational discounting models. If $w_{\text {cost }}=0.50, w_{\text {waste }}=0.25$ and $w_{\mathrm{CO} 2}=0.25$, the overcharges are lower than $2 \%$ for both cases. This means that including environmental impact in decision-making does not generate larger overcharges. Nevertheless, for the same cost weighting factors and for the repair of a port with a surface of $8,300 \mathrm{~m}^{2}$, a sustainable $\Delta t$ could reduce the waste generation by 15 and $84 \mathrm{~m}^{3}$ and the emissions by 10 and 46 tons of $\mathrm{CO}_{2}$, for the conventional and intergenerational discounting models (Figure 5). As mentioned before, the difference between the environmental impacts when intergenerational discounting is considered is due to the increase of $\Delta t$ that reduces the number of repairs. 
This paper presented a methodology for sustainable maintenance assessment and optimisation of coastal RC structures subjected to chloride ingress. It was developed within the framework of the MAREO project with the collaboration of different stakeholders involved during the whole structural lifetime. The proposed approach considered three criteria: (i) costs (including intergenerational issues), (ii) waste production, and (iii) $\mathrm{CO}_{2}$ emissions. The methodology uses compromise programming to deal with the multi-objective nature of the decision-making problem. This tool can be used to improve the sustainability performance of a maintenance strategy or to compare the sustainability of various strategies. Their application to a numerical example indicated that although environmentally friendly solutions increase global costs, they could reduce significantly $\mathrm{CO}_{2}$ emissions and waste.

\section{ACKNOWLEDGEMENTS}

The authors acknowledge the financial support the Région Pays de la Loire and French Ministry of Industry for supporting the MAREO project (Maintenance and REpair of concrete coastal structures: risk-based Optimisation).

\section{REFERENCES}

Alani A M, and Chen H-P. (2012). Reliability and optimised maintenance for sea defences. Proceedings of the ICE Maritime Engineering 165(2): 51-64. http://doi.org/10.1680/maen.2010.37

American Institute of Architects. (1999). Environmental Resource Guide. Wiley.

Bastidas-Arteaga E. (2010). Contribution for sustainable management of reinforced concrete structures subjected to chloride penetration. PhD Thesis, University of Nantes. Retrieved from http://tel.archives-ouvertes.fr/tel00796307

Bastidas-Arteaga E, Chateauneuf A, Sánchez-Silva M, Bressolette P, and Schoefs F. (2011). A comprehensive probabilistic model of chloride ingress in unsaturated concrete. Engineering Structures 33(3): 720-730. http://doi.org/10.1016/j.engstruct.2010.11.008

Bastidas-Arteaga E, and Schoefs F. (2012). Stochastic improvement of inspection and maintenance of corroding reinforced concrete structures placed in unsaturated environments. Engineering Structures 41: 50-62. http://doi.org/10.1016/j.engstruct.2012.03.011

Bastidas-Arteaga E, Schoefs F, Stewart M G, and Wang X. (2013). Influence of global warming on durability of corroding RC structures: A probabilistic approach. Engineering Structures 51: 259-266. http://doi.org/10.1016/j.engstruct.2013.01.006

Bastidas-Arteaga E, and Stewart M G. (2015a). Damage risks and economic assessment of climate adaptation strategies for design of new concrete structures subject to chloride-induced corrosion. Structural Safety 52: 4053. http://doi.org/10.1016/j.strusafe.2014.10.005

Bastidas-Arteaga E, and Stewart M G. (2015b). Economic Assessment of Climate Adaptation Strategies for Existing RC Structures Subjected to Chloride-Induced Corrosion. Structure and Infrastructure Engineering In press: 11 pages. http://doi.org/10.1080/15732479.2015.1020499

Boero J. (2010). Fiabilité des infrastructures portuaires: approche innovante d'analyse et de modélisation probabiliste des données d'inspection. PhD thesis, University of Nantes.

Boéro J, Schoefs F, Capra B, and Rouxel N. (2009). Technical management of French harbour structures - Part 1: Description of built assets. Revue Paralia. http://doi.org/10.5150/revue-paralia.2009.006

Bonnet S, Schoefs F, Ricardo J, and Salta M. (2009). Effect of error measurements of chloride profiles on reliability assessment. In H. Furuta, D. M. Frangopol, \& M. Shinozuka (Eds.), 10th International Conference on Structural Safety and Reliability. Osaka, Japan.

Cheung M M S, Zhang E X Q, and So K K L. (2009). Life-cycle cost management of concrete bridges. Proceedings of the ICE - Bridge Engineering 162(3): 103-117. http://doi.org/10.1680/bren.2009.162.3.103

Díaz Rato J L, Moyano Retamero J, and de Miguel Riestra M. (2008). Extension to the port of Gijón, Spain. Proceedings of the ICE - Maritime Engineering 161(4): 153-174. http://doi.org/10.1680/maen.2008.161.4.153

Du Plooy R, Palma Lopes S, Villain G, and Derobert X. (2013). Development of a multi-ring resistivity cell and multielectrode resistivity probe for investigation of cover concrete condition. NDT\&E International 54: 27-36.

Duckstein L. (1984). New directions in optimum structural design. In Atrek et al. (Ed.), (pp. 459-481). Wiley.

Duracrete. (1998). Modelling of Degradation, DuraCrete - Probabilistic Performance based Durability Design of Concrete Structures, EU - Brite EuRam III, Contract BRPR-CT95-0132, Project BE95-1347/R4-5.

International Energy Agency. (2007). Tracking Industrial Energy Efficiency and CO_2 Emissions - Energy Indicators. Paris: OECD.

IPCC. (2007). Climate Change 2007: The Physical Science Basis. Contribution of Working Group I to the Fourth Assessment Report of the Intergovernmental Panel on Climate Change. (S. Solomon, D. Qin, M. Manning, Z. 
Chen, M. Marquis, K. B. Averyt, ... H. L. Miller, Eds.). Cambridge, United Kingdom and New York, NY, USA: Cambridge University Press.

JCSS (Joint committee of structural safety). (2001). Probabilistic model code. Retrieved from www.jcss.ethz.ch

Kumar Mehta P. (1997). Durability : Critical Issues for the Future. Concrete International 19: 27-33.

Lefler F E, and Rey Romero V D. (2009). Reinforced concrete caissons for port structures in Spain. Proceedings of the ICE - Maritime Engineering 162(2): 73-81. http://doi.org/10.1680/maen.2009.162.2.73

Lounis Z. (2006). Risk-based maintenance optimization of aging highway bridge decks. Advances in Engineering Structures, Mechanics and Construction 140: 723-734.

Medeiros M H F, Gobbi A, Réus G C, and Helene P. (2013). Reinforced concrete in marine environment: Effect of wetting and drying cycles, height and positioning in relation to the sea shore. Construction and Building Materials 44: 452-457. http://doi.org/10.1016/j.conbuildmat.2013.02.078

Neville A. (1981). Properties of Concrete (3rd ed.). Harlow: Longman Scientific \& Technical.

Padgett J E, and Tapia C. (2013). Sustainability of Natural Hazard Risk Mitigation: Life Cycle Analysis of Environmental Indicators for Bridge Infrastructure. Journal of Infrastructure Systems 19(December): 395-408. http://doi.org/10.1061/(ASCE)IS

Page C, Short N, and Tarras A E. (1981). Diffusion of chloride ions in hardened cement pastes. Cement and Concrete Research 11(3): 395-406.

Prager M H, and Shertzer K W. (2006). Remembering the future: A commentary on "Intergenerational discounting: a new intuitive approach." Ecological Economics 60: 24-26.

Roelfstra G, Hajdin R, Adey B, and Brühwiler E. (2004). Corrosion evolution in bridge management systems and corrosion-induced deterioration. Journal of Bridge Engineering ASCE 9: 268-277.

Rosquoët F, Bonnet S, Schoefs F, and Khelidj A. (2006). Chloride propagation in concrete harbor. In J. Marchand, B. Bissonnette, R. Gagne, M. Jolin, \& F. Paradis (Eds.), 2nd International RILEM Symposium on Advances in Concrete through Science and Engineering. Quebec, Canada: RILEM Publications.

Saetta A, Scotta R, and Vitaliani R. (1993). Analysis of chloride diffusion into partially saturated concrete. ACl Materials Journal 90(5): 441-451.

Sánchez-Silva M, and Rosowsky D V. (2008). Risk, reliability and sustainability in the developing world. Proceedings of the ICE - Structures and Buildings. http://doi.org/10.1680/stbu.2008.161.4.189

Schoefs F. (2014). Modeling Inspection Uncertainties for On-site Condition Assessment using NDT Tools. In D. M. Frangopol \& Y. Tsompanakis (Eds.), Maintenance and Safety of Aging Infrastructure (pp. 573-619). CRC Press, Taylor \& Francis Group, London.

Schoefs F, Aury F, Vilvoisin P, Menard N, and Bastidas-Arteaga E. (2010). Repair of wharves in tidal area: mareo project. In M. Forde (Ed.), Structural Faults \& Repair 2010 (p. 7 pp). Edinburgh, Scotland, UK: Engineering Technics Press.

Sumaila U R, and Walters C. (2005). Intergenerational discounting: a new intuitive approach. Ecological Economics 52(2): 135-142. http://doi.org/10.1016/j.ecolecon.2003.11.012

Tapia C, and Padgett J E. (2015). Multi-objective optimisation of bridge retrofit and post-event repair selection to enhance sustainability. Structure and Infrastructure Engineering In press: 1-15. http://doi.org/10.1080/15732479.2014.995676

Thoft-Christensen P. (2009). Life-cycle cost-benefit (LCCB) analysis of bridges from a user and social point of view. Structure and Infrastructure Engineering 5: 49-57.

Torres-Luque M, Bastidas-Arteaga E, Schoefs F, Sánchez-Silva M, and Osma J F. (2014). Non-destructive methods for measuring chloride ingress into concrete: State-of-the-art and future challenges. Construction and Building Materials 68: 68-81. http://doi.org/10.1016/j.conbuildmat.2014.06.009

Tran T B, Bastidas-Arteaga E, Bonnet S, and Schoefs F. (2015). Parameter identification in chloride ingress from accelerated test using bayesian network. In 12th International Conference on Applications of Statistics and Probability in Civil Engineering, ICASP12 (p. 8 pp). Vancouver, Canada.

Val D, and Trapper P. (2008). Probabilistic evaluation of initiation time of chloride-induced corrosion. Reliability Engineering and System Safety 93: 364-372.

Van Noortwijk J M, and Frangopol D M. (2004). Life-Cycle Performance of Deteriorating Structures: Assessment, Design and Management. In D. M. Frangopol, E. Bruhwiler, M. H. Faber, \& B. Adey (Eds.), (pp. 384-391). ASCE.

Vu K A T, and Stewart M G. (2000). Structural reliability of concrete bridges including improved chloride-induced corrosion. Structural Safety 22: 313-333.

World Commission on Environment and Development. (1987). Our common future. Oxford: Oxford University Press. 


\section{List of Tables}

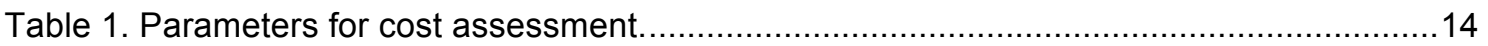

Table 2. Parameters to compute waste generation and $\mathrm{CO}_{2}$ emissions (Bastidas-Arteaga,

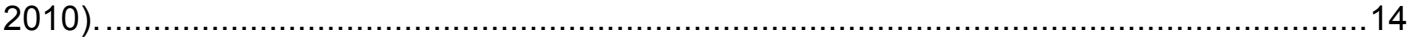

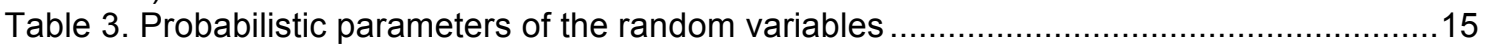

\section{List of Figures}

Figure 1. Cost-effective and sustainable formulation of repair techniques .............................16 Figure 2. Determination of the expected value of the times to preventive and corrective repair.16 Figure 3. Expected costs for the (a) conventional and (b) intergenerational discounting models.

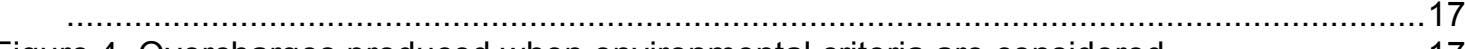

Figure 4. Overcharges produced when environmental criteria are considered.....................17

Figure 5. Influence of the cost weighting factor on the reduction of waste and emissions. ........17 
Table 1. Parameters for cost assessment.

\begin{tabular}{ll}
\hline Parameter & Value \\
\hline Initial cost of construction & 1000 units \\
Inspection cost & 5 units \\
Preventive repair cost & 150 units \\
Corrective repair cost & 300 units \\
Conventional discount rate, $r$ & $5 \%$ \\
Intergenerational discount rate, $r_{l}$ & $3 \%$ \\
Generation length, $G$ & $25 \mathrm{yr}$ \\
Analysis period, $T_{a}$ & $100 \mathrm{yr}$ \\
\hline
\end{tabular}

Table 2. Parameters to compute waste generation and $\mathrm{CO}_{2}$ emissions (E. Bastidas-Arteaga, 2010).

\begin{tabular}{ll}
\hline Parameter & Value \\
\hline Surface of the structure to repair & $10,000 \mathrm{~m}^{2}$ \\
Waste generated to repair $1 \mathrm{~m}^{3}$ of concrete & $1.3 \mathrm{~m}^{3}$ \\
$\mathrm{CO}_{2}$ released to inspect $1 \mathrm{~m}^{3}$ of concrete & $4 \mathrm{~kg} \mathrm{of} \mathrm{CO}$ \\
$\mathrm{CO}_{2}$ released to repair $1 \mathrm{~m}^{3}$ of concrete & $620 \mathrm{~kg} \mathrm{of} \mathrm{CO}$ \\
\hline
\end{tabular}


Table 3. Probabilistic parameters of the random variables

\begin{tabular}{|c|c|c|c|c|c|}
\hline Variable & Units & Distribution & Mean & COV & References \\
\hline $\begin{array}{l}\text { Chloride diffusion coefficient } \\
\text { (original material), } D_{c, \text { ref-ori }}\end{array}$ & $\mathrm{m}^{2} / \mathrm{s}$ & log-normal & $3 \cdot 10^{-11}$ & 0.20 & $\begin{array}{c}\text { (Duracrete, 1998; Saetta } \\
\text { et al., 1993; Val and } \\
\text { Trapper, 2008) }\end{array}$ \\
\hline $\begin{array}{l}\text { Chloride diffusion coefficient } \\
\text { (repair material), } D_{c, \text { ref-rep }}\end{array}$ & $\mathrm{m}^{2} / \mathrm{s}$ & log-normal & $4.5 \cdot 10^{-11}$ & 0.20 & (Schoefs et al., 2010) \\
\hline $\begin{array}{l}\text { Concentration threshold for } v \\
\text { corrosion initiation, } C_{t h}\end{array}$ & wt\% cem. & normal $^{a}$ & 0.5 & 0.20 & $\begin{array}{c}\text { (Emilio Bastidas-Arteaga } \\
\text { and Schoefs, 2012; } \\
\text { Duracrete, 1998) }\end{array}$ \\
\hline $\begin{array}{l}\text { Activation energy of the chloride } \\
\text { diffusion process, } U_{c}\end{array}$ & $\mathrm{~kJ} / \mathrm{mol}$ & $\begin{array}{l}\text { beta on } \\
{[32 ; 44.6]}\end{array}$ & 41.8 & 0.10 & $\begin{array}{l}\text { (E. Bastidas-Arteaga et } \\
\text { al., 2011; Duracrete, } \\
\text { 1998; Page et al., 1981) }\end{array}$ \\
\hline Ageing factor, $m$ & & beta on $[0 ; 1]$ & 0.15 & 0.30 & $\begin{array}{l}\text { (Duracrete, 1998; Val } \\
\text { and Trapper, 2008) }\end{array}$ \\
\hline $\begin{array}{l}\text { Reference humidity diffusion } \\
\text { coefficient, } D_{h, \text { ref }}\end{array}$ & $\mathrm{m}^{2} / \mathrm{s}$ & log-normal & $3 \cdot 10^{-10}$ & 0.20 & $\begin{array}{l}\text { (Saetta et al., 1993; Val } \\
\text { and Trapper, 2008) }\end{array}$ \\
\hline $\begin{array}{l}\text { Parameter representing the ratio } \\
D_{h, \text { min }} / D_{h, \text { max }}, \alpha_{0}\end{array}$ & - & $\begin{array}{c}\text { beta on } \\
{[0.025 ; 0.1]}\end{array}$ & 0.05 & 0.20 & (Val and Trapper, 2008) \\
\hline $\begin{array}{l}\text { Parameter characterizing the } \\
\text { spread of the drop in } D_{h}, n\end{array}$ & - & $\begin{array}{c}\text { beta on } \\
{[6 ; 16]}\end{array}$ & 11 & 0.10 & (Val and Trapper, 2008) \\
\hline Thermal conductivity of concrete, $\lambda$ & $\mathrm{W} /\left(\mathrm{m}^{\circ} \mathrm{C}\right)$ & $\begin{array}{l}\text { beta on } \\
{[1.4 ; 3.6]}\end{array}$ & 2.5 & 0.05 & (Neville, 1981) \\
\hline $\begin{array}{l}\text { Specific heat capacity of concrete, } \\
c_{q}\end{array}$ & $\mathrm{~J} /\left(\mathrm{kg}^{\circ} \mathrm{C}\right)$ & $\begin{array}{l}\text { beta on } \\
{[840 ; 1170]}\end{array}$ & 1000 & 0.10 & (Neville, 1981) \\
\hline Density of concrete, $\rho_{c}$ & $\mathrm{~kg} / \mathrm{m}^{3}$ & Normal $^{\mathrm{a}}$ & 2400 & 0.04 & $\begin{array}{l}\text { (JCSS (Joint committee } \\
\text { of structural safety), } \\
\text { 2001) }\end{array}$ \\
\hline
\end{tabular}

${ }^{a}$ truncated at 0 

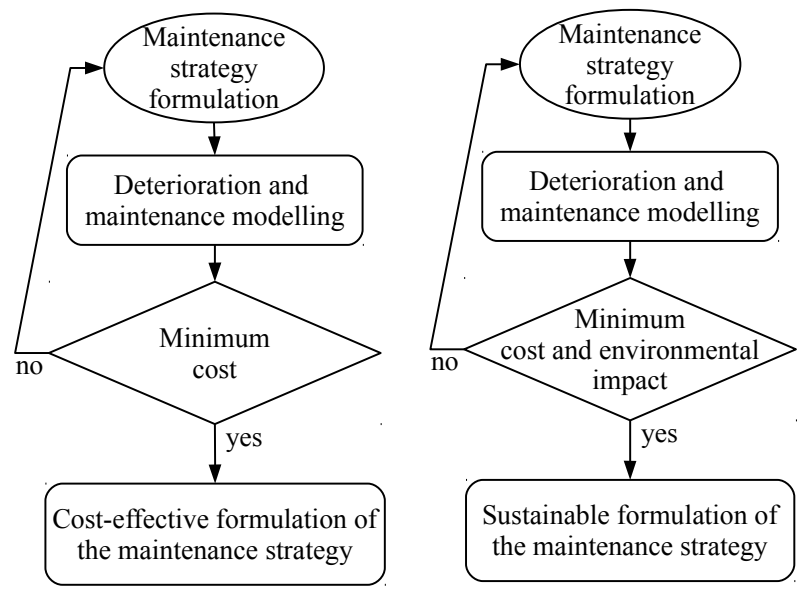

Figure 1. Cost-effective and sustainable formulation of repair techniques
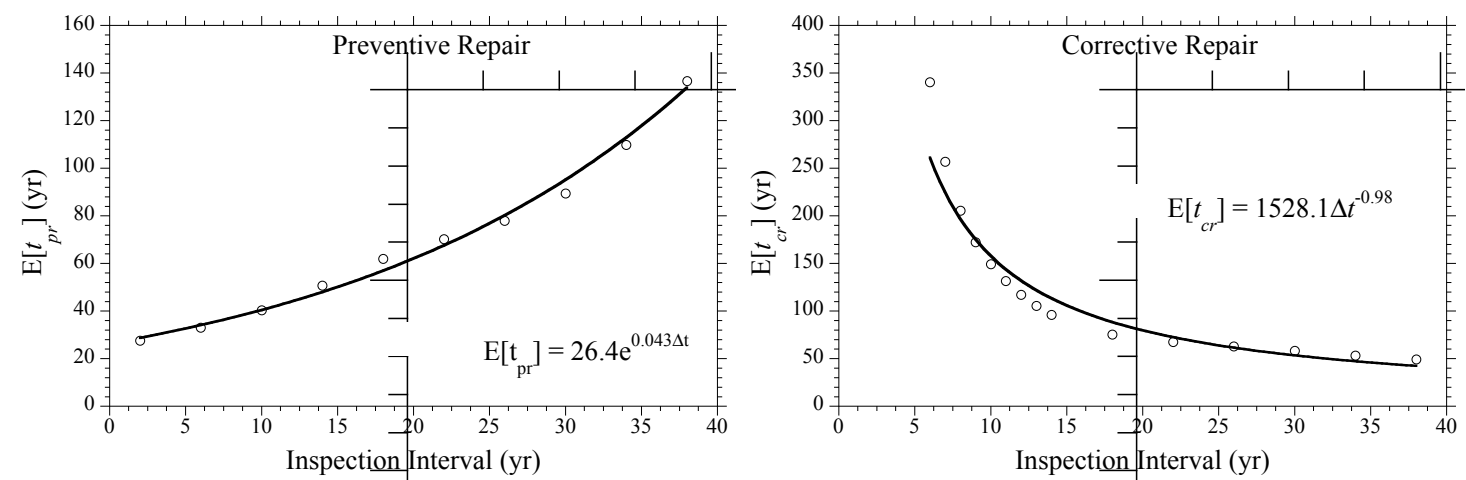

Figure 2. Determination of the expected value of the times to preventive and corrective repair. 
(a)

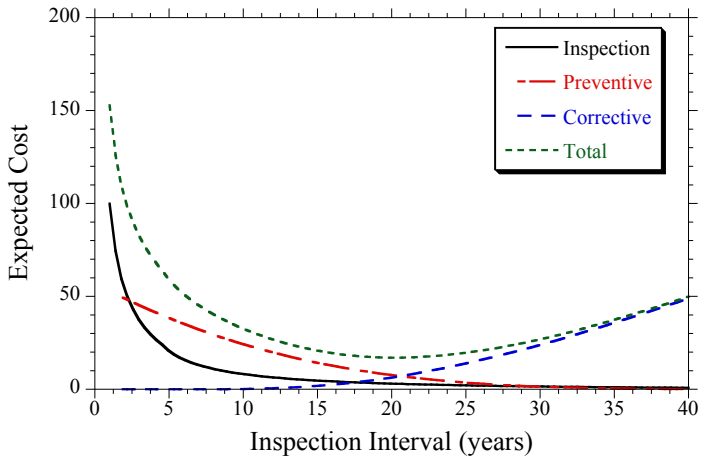

(b)

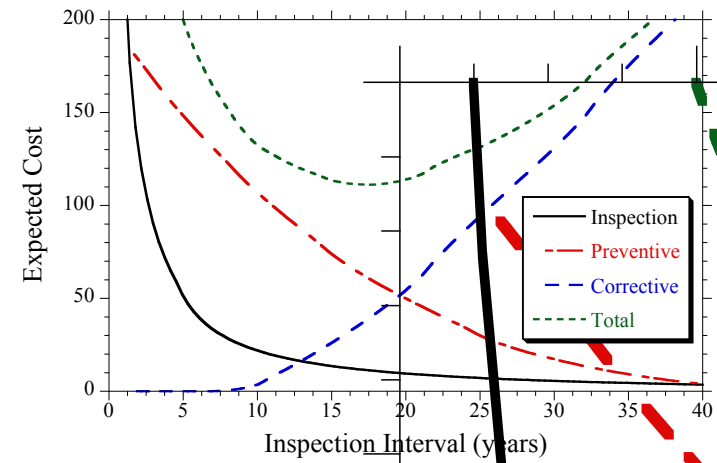

Figure 3. Expected costs for the (a) conventional and (b) intergenerational discounting models.

(a)

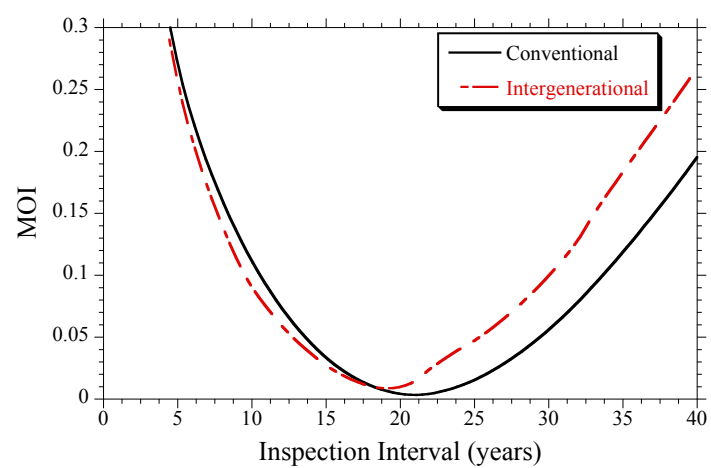

(b)

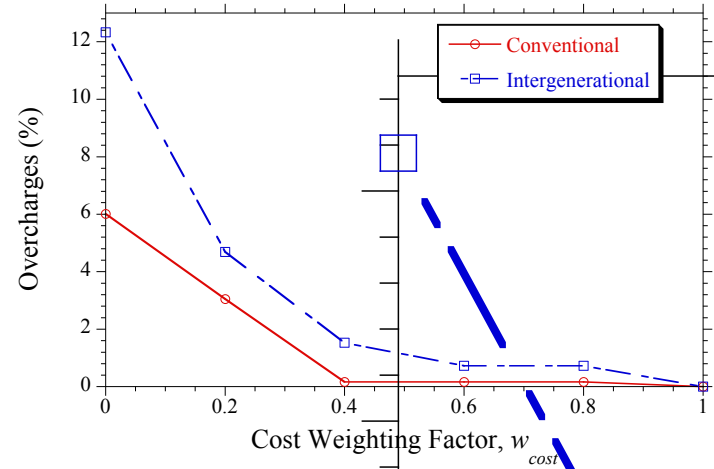

Figure 4. Consideration of environmental criteria: (a) Multi-Objective Index, (b) Overcharges.
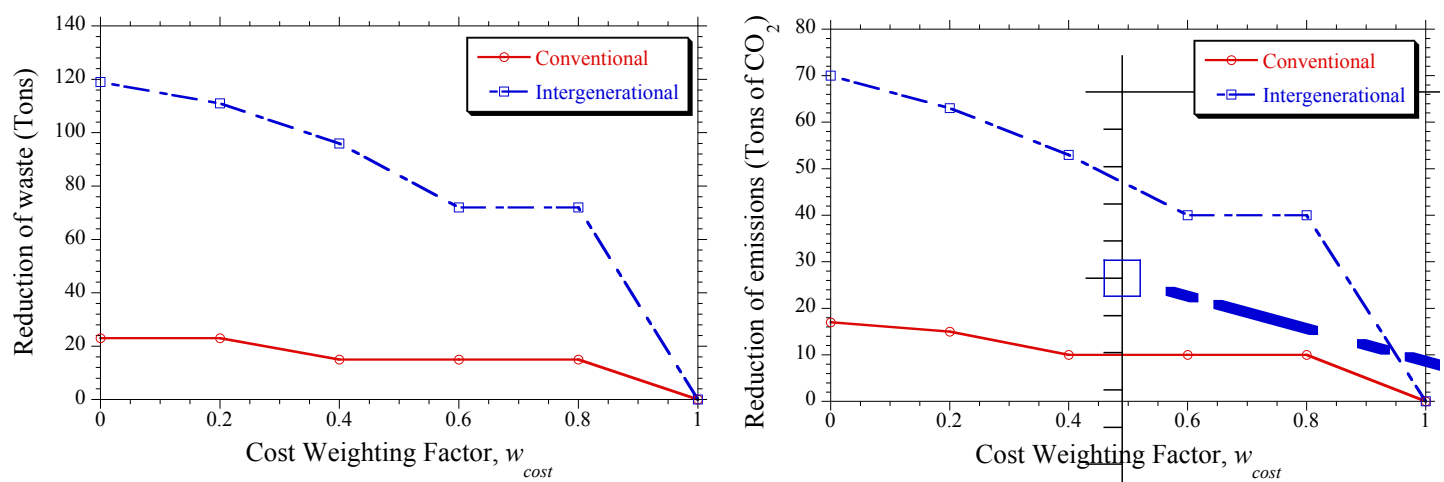

Figure 5. Influence of the cost weighting factor on the reduction of waste and emissions. 